\title{
An update on research priorities in hydrocephalus: overview of the third National Institutes of Health-sponsored symposium "Opportunities for Hydrocephalus Research: Pathways to Better Outcomes"
}

\author{
*James P. McAllister II, PhD, ${ }^{1}$ Michael A. Williams, MD, ${ }^{3}$ Marion L. Walker, MD, ${ }^{4}$ \\ John R. W. Kestle, MD, ${ }^{4}$ Norman R. Relkin, MD, PhD, ${ }^{5}$ Amy M. Anderson, BSN, RN, ${ }^{6}$ \\ Paul H. Gross, BA, ${ }^{7}$ and Samuel R. Browd, MD, PhD, ${ }^{2}$ for the Hydrocephalus Symposium \\ Expert Panel
}

\begin{abstract}
1Department of Neurosurgery, Division of Pediatric Neurosurgery, Washington University School of Medicine and St. Louis Children's Hospital, St. Louis, Missouri; '2Departments of Neurosurgery and Bioengineering, University of Washington and Seattle Children's Hospital, Seattle, Washington; 'Department of Neurology, The Sandra and Malcolm Berman Brain \& Spine Institute

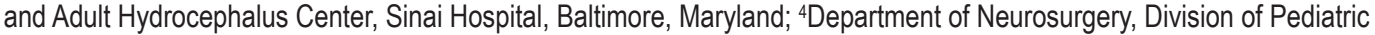
Neurosurgery, University of Utah, Primary Children's Medical Center, Salt Lake City, Utah; ${ }^{5}$ Department of Neurology, Weill Cornell Medical College, New York, New York; ${ }^{6}$ Department of Neurosurgery, Seattle Children's Hospital, Seattle, Washington; and ${ }^{7}$ Hydrocephalus Association, Bethesda, Maryland
\end{abstract}

Building on previous National Institutes of Health-sponsored symposia on hydrocephalus research, "Opportunities for Hydrocephalus Research: Pathways to Better Outcomes" was held in Seattle, Washington, July 9-11, 2012. Plenary sessions were organized into four major themes, each with two subtopics: Causes of Hydrocephalus (Genetics and Pathophysiological Modifications); Diagnosis of Hydrocephalus (Biomarkers and Neuroimaging); Treatment of Hydrocephalus (Bioengineering Advances and Surgical Treatments); and Outcome in Hydrocephalus (Neuropsychological and Neurological). International experts gave plenary talks, and extensive group discussions were held for each of the major themes.

The conference emphasized patient-centered care and translational research, with the main objective to arrive at a consensus on priorities in hydrocephalus that have the potential to impact patient care in the next 5 years. The current state of hydrocephalus research and treatment was presented, and the following priorities for research were recommended for each theme. 1) Causes of Hydrocephalus-CSF absorption, production, and related drug therapies; pathogenesis of human hydrocephalus; improved animal and in vitro models of hydrocephalus; developmental and macromolecular transport mechanisms; biomechanical changes in hydrocephalus; and age-dependent mechanisms in the development of hydrocephalus. 2) Diagnosis of Hydrocephalus-implementation of a standardized set of protocols and a shared repository of technical information; prospective studies of multimodal techniques including MRI and CSF biomarkers to test potential pharmacological treatments; and quantitative and cost-effective CSF assessment techniques. 3) Treatment of Hydrocephalus-improved bioengineering efforts to reduce proximal catheter and overall shunt failure; external or implantable diagnostics and support for the biological infrastructure research that informs these efforts; and evidencebased surgical standardization with longitudinal metrics to validate or refute implemented practices, procedures, or tests. 4) Outcome in Hydrocephalus-development of specific, reliable batteries with metrics focused on the hydrocephalic

ABBREVIATIONS CPC = choroid plexus cauterization; DTI = diffusion tensor imaging; ETV = endoscopic third ventriculostomy; HCRN = Hydrocephalus Clinical Research Network; ICP = intracranial pressure; iNPH = idiopathic NPH; LPA = lysophosphatidic acid; NIH = National Institutes of Health; NPC = neural precursor cell; NPH = normal pressure hydrocephalus; NSC = neural stem cell; PreOL = precursor oligodendroglia; RCT = randomized controlled trial; SVZ = subventricular zone; TNF = tumor necrosis factor; $\mathrm{VP}=$ ventriculoperitoneal; $\mathrm{VZ}$ = ventricular zone.

SUBMITTED October 30, 2013. ACCEPTED December 9, 2014

INCLUDE WHEN CITING Published online June 19, 2015; DOI: 10.3171/2014.12.JNS132352.

DISCLOSURE Mr. Gross states that he is the cofounder and was a significant donor to the Hydrocephalus Clinical Research Network and has been a significant donor to Seattle Children's Hospital. The authors state that financial support was provided by the National Institutes of Health, the Hydrocephalus Association, the Hydrocephalus Clinical Research Network, Seattle Children's Hospital and Research Institute, the University of Washington, and the Seattle Children's Hydrocephalus Research Guild. Corporate sponsors included Medtronic Neurologic Technologies, Rudi Schulte Research Institute, Codman Neuro, Integra LifeSciences Corporation, University of Washington Department of Neurological Surgery, Seattle Children's Research Institute, and System Science, Inc.

* Drs. McAllister and Browd contributed equally to this work. 
patient; measurements of neurocognitive outcome and quality-of-life measures that are adaptable, trackable across the growth spectrum, and applicable cross-culturally; development of comparison metrics against normal aging and sensitive screening tools to diagnose idiopathic normal pressure hydrocephalus against appropriate normative age-based data; better understanding of the incidence and prevalence of hydrocephalus within both pediatric and adult populations; and comparisons of aging patterns in adults with hydrocephalus against normal aging patterns.

http://thejns.org/doi/abs/l10.3171/2014.12.JNS132352

KEY WORDS hydrocephalus; symposium; conference; National Institutes of Health; research

A $\mathrm{s}$ reported in the priorities from the 2005 National Institutes of Health (NIH) hydrocephalus workshop $^{133}$ and presented at the $2009 \mathrm{NIH}$-sponsored workshop in Baltimore, Maryland, the clinical and scientific perspective of hydrocephalus has shifted from the oversimplified view of hydrocephalus as a "plumbing problem" that is adequately managed with a shunt to that of an exceptionally complex, multifactorial disorder that involves novel and poorly understood injury and recovery mechanisms. The white paper generated from the 2005 NIH hydrocephalus symposium provided a broad overview of the priorities within the hydrocephalus community and set the framework for the last several years in terms of research focus and funding initiatives both within $\mathrm{NIH}$ and within nongovernmental funding agencies.

The most recent conference, "Opportunities for Hydrocephalus Research: Pathways to Better Outcomes," held in Seattle, Washington, July 9-11, 2012, was organized to review the current state of the field and to identify which areas of research could produce short-term clinical progress and which would require a longer-term strategy. Clearly, both efforts would benefit from multidisciplinary approaches, so an additional goal of the conference was to foster collaborations and data sharing.

Presenters were invited based on the initial review and acceptance of an NIH U13 Conference grant (1U13NS080503-01) and recommendations from the Steering Committee, which consisted of experienced investigators in all aspects of clinical and basic research in hydrocephalus, a program director at NIH, and the CEO of the Hydrocephalus Association. The Hydrocephalus Symposium Expert Panel (see Appendix) also provided input on who should present. The registration to the symposium was open to any attendees. Thus, a diverse group of 65 active investigators in hydrocephalus participated.

This report will summarize the research priorities generated by the conference attendees in four broad categories: 1) causes of hydrocephalus; 2) diagnosis of hydrocephalus; 3) treatment of hydrocephalus; and 4) outcome in hydrocephalus. The remaining discussion is organized to highlight the background information presented at the meeting and to summarize the consensus discussion that resulted in the summary research priority recommendations. The references cited highlight the presentations and discussion and are not intended to be a comprehensive review of the field. It is important to note that all of the participants in this conference had an opportunity to express their opinions, especially in the postplenary group discussions. Numerical rankings of responses from the entire audience were obtained during the final discussions and were used to identify consensus priorities in this report. Nevertheless, this work reflects the opinions of the experts who attended this conference rather than a systematic, bal- anced review of the literature or the field. The goal of the paper is to present the conclusions from the conference to the larger neurosurgical and medical community, rather than to serve as a comprehensive review of hydrocephalus research, a topic that could fill an entire volume. Additional objective international perspectives on hydrocephalus research can be found in reviews by Stagno et al., McAllister, Andresen and Juhler, and Robinson.,79,101,110 The scientific program agenda, conference structure, meeting objectives, list of attendees, conference leadership, and slides for each presentation are available on the website of the Hydrocephalus Association (http://www.hydroassoc. org/2012-seattle-conference-program/).

\section{Theme 1: Causes of Hydrocephalus Genetics}

Judging from the plethora of information on the underlying genes in human and mouse hydrocephalus, the genetic basis of hydrocephalus appears to be a daunting problem. Early pattern formation genes such as SHH, ZIC2, PAX6, and $W N T 1$, neuronal path-finding genes such as LICAM, genes related to cortical development such as POMT1, and those related to growth regulation such as PIK3CA and AKT3 have been implicated. 1,3,7,10,29,52,53,72,84,85,91,103,122 Developmental disorders presenting with hydrocephalus include neural tube disorders, forebrain and hindbrain developmental disorders, brain growth disorders, and cortical malformations. Alterations in the choroid plexus, ependyma, aqueduct, ventricles, and extraaxial spaces can also lead to hydrocephalus. The study of known human genetic syndromes that have hydrocephalus as a component of the disease represents a pathway to understand the complex polymorphisms that lead to hydrocephalus.

Abnormal neurogenesis in fetal-onset hydrocephalus in both humans and animal models represents an avenue for stem cell therapy. It was suggested that a common pathogenetic mechanism involving junctional complexes starts early in embryonic life with disruption of the neural stem cells (NSCs) and neural precursor cells (NPCs) forming the ventricular zone (VZ) and subventricular zone (SVZ), respectively. ${ }^{102}$ NSCs and NPCs have been collected from the CSF of hydrocephalic human fetuses and mutant HTx rats and grown into neurospheres. The cells forming these neurospheres express pathological features, thus becoming a valuable tool to study cellular and molecular defects in animal and human neurogenesis and providing a platform for future drug studies in hydrocephalus. ${ }^{36}$

Models of the disrupted VZ demonstrate that repair mechanisms are present in hydrocephalic animals and humans. ${ }^{20,100}$ In congenital hydrocephalus, reactive astrocytes replace absent ependymal cells at the ventricular border. The role of these astrocytes in the production of 
proinflammatory and neuroprotective factors is currently under study. In animal models, the reactive astrocytes can be involved in the production of tumor necrosis factor $-\alpha$ $(\mathrm{TNF} \alpha)$ that could have a role in hippocampal and neocortical impairment. Thus, $\mathrm{TNF}^{114}$ and transforming growth factor- $\beta 1^{13,51,73,137}$ may be suitable biomarkers for diagnosis and prognosis in different forms of hydrocephalus.

\section{Pathophysiological Modifications}

A cardinal feature of ventriculomegaly is that it leads to the gradual destruction of periventricular white matter axons through hypoxic, ischemic, and mechanical stress mechanisms. ${ }^{22-25,27,57,79,80,136}$ Metabolic disturbances contribute to reversible dysfunction, but the clinical syndrome of hydrocephalic brain dysfunction may be due predominantly to a subcortical disconnection syndrome. Possible causes of ventricular dilation include obstructed CSF flow with associated increased CSF pulsatility. ${ }^{123}$ Small forces repeatedly applied to the brain can lead to ventricular enlargement. Reduced cerebral blood flow occurs in children and adults with hydrocephalus but improves after shunt placement and normalization of intracranial pressure (ICP). Metabolic dysregulation may lead to oligodendroglial and axonal damage. Calcium-related proteolysis and cell death occur analogous to injury cascades seen in brain ischemia and trauma. ${ }^{6,46,58}$ In the developing brain, hydrocephalus can lead to delayed or reduced myelination, and adverse effects on periventricular germinal matrix tissue have the potential to impair brain development. The degree and type of damage are related to the age at the time of insult, the rate of ventricular enlargement, and the associated rise in ICP with decrement in cerebral perfusion pressure. Some changes are reversible with ventricular shunt placement and reduction in ICP. If axonal destruction has already occurred, improvements are less likely with shunt placement. Targets of pharmacological interventions aim at reducing CSF production, enhancing CSF flow and absorption, decreasing neuroinflammation, ${ }^{13,81}$ providing neuroprotection, and improving recovery/regeneration of damaged tissues. ${ }^{28,60,78}$

Recurrent hypoxia-ischemia is common in critically ill preterm infants, but maturation of oligodendrocytes affords increased resistance to this condition. In the setting of cerebral palsy, the declining burden of necrosis in white matter injury raises the question of whether myelination failure is from selective loss of precursor oligodendroglia (PreOL) that are required to generate mature oligodendroglia and myelin. PreOLs are selectively damaged by oxidative stress, and surviving PreOLs can fail to generate myelin in chronic lesions. ${ }^{3,106}$ PreOL maturation arrest is correlated with astrogliosis; glial scars contain high CD44 expression that blocks PreOL differentiation and prevents remyelination. Thus, as the brain matures, PreOL-rich chronic white matter lesions may retain persistent susceptibility to hypoxia-ischemia. Furthermore, high-field MRI permits unprecedented resolution of white matter injury previously not detected clinically at lower field strengths, raising the possibility that therapies directed at myelin regeneration and repair could be monitored over time in preterm survivors.

Lysophosphatidic acid (LPA) is prominent during hem- orrhage where high concentrations, as well as hypoxia, can overactivate LPA receptors present on prenatal NPCs. Studies in animals have identified altered LPA signaling that disrupts the normal development of NPCs, suggesting that therapeutic intervention targeting LPA receptors could provide medical treatments for some forms of hydrocephalus.

\section{Areas of Promise and Recommendations for Causes of Hydrocephalus in the Next 5 Years}

The consensus of the attendees strongly favored the need for more research in CSF absorption, production, and related drug therapies (Table 1). Two topics are especially important: 1) pathogenesis of human hydrocephalus, including CSF physiology, and 2) improved animal and in vitro models of hydrocephalus. Moderate interest was also shown in developmental and macromolecular transport mechanisms, biomechanical changes in hydrocephalus, and age-dependent mechanisms in the development of hydrocephalus.

\section{Theme 2: Diagnosis of Hydrocephalus}

From a clinical perspective, the diagnosis of hydrocephalus has remained a relatively simplistic endeavor, encompassing both clinical signs and symptoms and basic neuroimaging modalities. This theme brought forward new concepts, ideas, and technology that have the potential not only to advance our ability to diagnosis hydrocephalus, but also to track meaningful metrics of diagnostic and treatment success.

\section{Biomarkers}

Few biomarkers accomplish the goal of measuring and evaluating normal biological processes, pathogenic processes, or pharmacological responses to therapeutic interventions cleanly or individually. The use of complementary biomarkers within a single disease is likely to provide a more comprehensive assessment of the disease and its course.

Molecules and other predictors of outcome represent an important focus for future research in biomarkers. Normal pressure hydrocephalus (NPH) remains an undertreated diagnosis based on clinical symptoms and knowledge of ICP in association with basic imaging modalities. While clinical consensus guidelines have been advanced, the method of diagnosis is invasive, often requiring external lumbar drainage trials. Various investigations have examined CSF peptides, neurotransmitters, metabolites, and proteins as potential biomarkers. ${ }^{119}$ The most promising biomarkers to date include Tau protein, amyloid- $\beta$, TNF, lactate, sulfatide, and neurofilament triple protein. ${ }^{48,64,65,67,83,86,89,93,104,112-117}$ A possible solution to the difficulty of interpreting these results is the use of ratios and/or panels of biomarkers and recording CSF production rate. Similarly, the methods of collection and storage of samples are critical. The ability to follow biomarkers across cohorts, stratify risk factors, and, someday, personalize care is among the translational benefits biomarkers afford in the diagnosis and care of patients with NPH.

CSF proteomics offer the ability to characterize the CSF proteome, identify candidate diagnostic biomark- 
ers of hydrocephalus or therapeutic efficacy, identify biomarkers that predict cognitive outcome, elucidate the mechanisms underlying developmental delay, and identify target genes for genetic analysis quickly. ${ }^{69,70,89,130}$ Numerous proteins involved in nervous system development and function have been identified in CSF, including neural cadherin, neural cell adhesion molecules, neurocan, and neuroserpin. Alterations in CSF proteomic profiles have been noted in patients with impaired cognition. Human ventricular CSF may contain a protein signature that could be used to predict outcome in hydrocephalus patients. Future goals include 1) sharing samples between clinical and experimental research centers to validate techniques and findings; 2) developing guidelines for sample storage, mass spectrometry, and data end points; and 3) supporting these overall goals with governmental and nongovernmental funding allocation.

\section{Neuroimaging}

Challenges arise within the standard uses of imaging when determining whether NPH is the result of ventricular enlargement or cerebral atrophy. ${ }^{87}$ Neuroimaging is essential to the diagnosis of NPH, but visual inspection without advanced techniques is subjective, with limited power to distinguish NPH from other conditions. Nevertheless, a recent study has shown that diffusion tensor imaging (DTI) can differentiate among NPH, Alzheimer disease, and Parkinson disease. ${ }^{45}$ Advanced MRI methodologies can also guide the development of pharmacological treatments by providing quantitative measures of treatment.

MRI findings suggest that in some patients idiopathic NPH (iNPH) is a two-hit disease, i.e., benign external hydrocephalus in infancy followed by deep white matter ischemia in late adulthood. Patients with iNPH have larger than normal intracranial volumes and increased apparent diffusion coefficients in the white matter ${ }^{95}$ supporting the possibility that at least partial CSF outflow occurs through extracellular spaces. Phase-contrast MRI can quantify aqueductal CSF flow and, along with other imaging correlates such as CSF flow voids, can predict shunt responsiveness in NPH. ${ }^{8,14,134}$

What is often missing in development and validation of diagnostic and prognostic imaging techniques is the link between these techniques and the underlying mechanisms responsible for any imaging changes. Various MRI techniques, such as phase-contrast MRI, DTI, and elastography, hold great promise in identifying hydrocephalus pathophysiology, guiding clinical management, and developing alternative therapies. ${ }^{45}$ Cerebral blood flow represents an important marker that can be assessed with a variety of techniques, including PET, ${ }^{88}$ SPECT, and MRI. $.19,40,74$ Standardization of techniques is also critical for multiple centers to correlate various outcome measures.

\section{Areas of Promise and Recommendations for the Diagnosis of Hydrocephalus in the Next 5 Years}

The two most important issues in diagnoses are implementation of a standardized set of protocols and a shared repository of technical information (Table 2). Nearly as important are prospective studies with multimodal tech- niques (e.g., MRI and CSF biomarkers to test potential pharmacological treatments), and quantitative and costeffective assessment techniques (e.g., CSF diagnosis). The interest in a shared repository with standardized samples was driven largely by the technical and experimental progress made recently in the evaluation of CSF biomarkers. This initiative would require identification of consensus priorities for coordinated and focused biomarker development, validation of promising biomarkers through multiinstitutional networks to accelerate clinical implementation, and advocacy for funding to support technology and provide resources for biomarker discovery.

Likewise, the potential that newer noninvasive MRI techniques could bring to the diagnosis of hydrocephalus was clearly apparent. It is encouraging that noninvasive phase-contrast MRI has the ability to calculate ICP indirectly; this advancement could dramatically reduce the need for invasive measurements of ICP, which are not routinely performed currently in North America because of ethical concerns.

\section{Theme 3: Treatment of Hydrocephalus}

The continuing high complication rates and new advances prompted a renewed focus on better treatments. In addition, previous conferences have not included bioengineering advances, ${ }^{133}$ which are fundamental to the development of optimal surgical devices.

\section{Bioengineering Advances}

Despite many advances in the design of the CSF shunt, there have been few improvements in the rate of shunt malfunction, ${ }^{75}$ with greater than $40 \%$ of first-time shunts failing within 2 years. . $^{17,18,90,96,97,118}$

Shunt obstruction remains a critical challenge and represents the most common point of failure in patients with shunt-dependent hydrocephalus. ${ }^{11}$ Current options for solving this problem include the use of improved catheter geometry, the use of antifouling coatings, and active methods to fight in-growth or remove growth after it occurs. ${ }^{39}$ Despite various attempts to alter the proximal catheter geometry, none have proven superior. Similarly, catheter coatings have been tried as a means to reduce obstruction, but these prototypes have not been tested clinically. Little to no activity has occurred to address the problem of valve obstruction. Models of flow dynamics, an understanding of cellular and tissue responses to implanted catheters and valves, and the development of novel bioengineering solutions are the pathways to improve upon the recalcitrant problem of obstruction-based device failures.

Improved diagnostics save the clinician from determining device failure by clinical signs/symptoms and rudimentary imaging studies. Opportunities exist to incorporate pressure and flow sensors into devices. ${ }^{71,76}$ The most advanced technologies in this arena have used cutaneous diagnostics to assess shunt function by using CSF flow. ${ }^{59,86}$ Issues arise related to the low range of ICP values needing to be registered, accuracy, resolution, and drift. ${ }^{82}$

Smart shunts represent another area that could provide tangible benefits to patients with hydrocephalus. The common vision of a "smart" shunt includes incorporated sen- 
TABLE 1. Areas of promise and recommendations for hydrocephalus research on causes of hydrocephalus in the next 5 years

\begin{tabular}{|c|c|c|}
\hline Theme & Areas of Promise & Recommendations \\
\hline Genetics & $\begin{array}{l}\text { - Determine whether fetal hydrocephalus is a stem cell pathol- } \\
\text { ogy } \\
\text { - Determine the pathogenetic roles that VZ and SVZ disruption } \\
\text { play } \\
\text { - Identify genetic factors in primary and secondary hydro- } \\
\text { cephalus } \\
\text { - Identify epigenetic factors in all forms of hydrocephalus }\end{array}$ & $\begin{array}{l}\text { - Support multicenter studies that correlate genetic changes in } \\
\text { animal models of congenital hydrocephalus with those found } \\
\text { in clinical hydrocephalus } \\
\text { - Promote pathogenetic studies that focus on clinically relevant } \\
\text { forms of congenital human hydrocephalus }\end{array}$ \\
\hline $\begin{array}{l}\text { Pathophysiological } \\
\text { Modifications }\end{array}$ & $\begin{array}{l}\text { - Identify/clarify the multifactorial injury mechanisms under- } \\
\text { lying the pathogenesis of hydrocephalus, including the } \\
\text { pathophysiology of white matter in hydrocephalus and other } \\
\text { neurological disorders } \\
\text { - Improvements in the identification and collaborative use of } \\
\text { preclinical models of hydrocephalus } \\
\text { - Pharmacological interventions to supplement surgical treat- } \\
\text { ments for preventing neuronal injury and promoting recovery } \\
\text { of function in all forms of hydrocephalus }\end{array}$ & $\begin{array}{l}\text { - Support experimental and clinical studies that identify both } \\
\text { normal and abnormal CSF production, flow, and absorption } \\
\text { - Support translational studies on the pathogenesis and patho- } \\
\text { physiology of human hydrocephalus } \\
\text { - Promote experimental studies (both in vivo and in vitro) on } \\
\text { improved (translational) models of hydrocephalus } \\
\text { - Promote studies on the development of pharmacological } \\
\text { therapies for all forms of hydrocephalus }\end{array}$ \\
\hline
\end{tabular}

sors (flow or pressure), a pump or valve to regulate flow of CSF, installed electronics to drive a controlling algorithm, the ability to measure various parameters, two-way communication, and implanted power sources such as a battery. Described in concept and detail decades ago (reviewed by Lutz et al. ${ }^{75}$ ), the technological hurdles include low-power draw components, pressure sensors that are implantable with little to no drift, and importantly, appropriate algorithms for controlling such devices. Advanced models of CSF dynamics are needed to test smart shunts on the bench and in vitro.

A perspective on business development pathways related to hydrocephalus emphasizes the need for partnership between the scientist, engineer, clinician, and industry. Two important factors have caused innovation to stagnate in this market sector: 1) The small market relative to other extensive neurosurgical instrumentation procedures and 2) insufficient data on CSF physiology to develop improved designs. Experience with the development of the Delta and Strata valves by PS Medical and recent experimental studies on the use of microporous materials for catheters illustrate the difficulties faced by small and large shunt companies. Nevertheless, there is great potential for the development of antifouling and self-cleaning catheters, ${ }^{66}$ "smart" valves with telemetry and pressure sensors that do not drift, $33,34,88,92,111,131$ reinforced kink-resistant catheters, and suture-less connectors.

\section{Surgical Advances}

For more than 10 years, accurate catheter placement and insertion site have been asserted to improve ventriculoperitoneal shunt (VP) shunt survival. Freehand insertions show that only 50\% are placed with high accuracy, ${ }^{41,55}$ but the value of costly navigation systems remains in question. ${ }^{68} \mathrm{~A}$ randomized controlled trial (RCT) faces obstacles including surgeon agreement to randomize when adjunct technology is known to be more accurate for catheter placement. ${ }^{132}$

\section{TABLE 2. Areas of promise and recommendations for hydrocephalus research on diagnosis of hydrocephalus in the next 5 years}

\begin{tabular}{|c|c|c|}
\hline Theme & Areas of Promise & Recommendations \\
\hline Biomarkers & $\begin{array}{l}\text { - Many centers have the ability to collect CSF and tissue from } \\
\text { pediatric and adult hydrocephalic patients; this capacity could } \\
\text { produce excellent multicenter studies if standardized protocols } \\
\text { are followed } \\
\text { - Improved quantitative and cost-effective assessment techniques } \\
\text { for evaluating CSF and tissue now allow excellent data analyses } \\
\text { - Development of home-based diagnostics }\end{array}$ & $\begin{array}{l}\text { - Implementation of a standardized set of acquisition protocols } \\
\text { and a shared repository for CSF and tissue from all types of } \\
\text { hydrocephalic cases } \\
\text { - Support for multidisciplinary and multimodal (neuroimaging } \\
\text { and proteomics) studies coupled with outcome analyses }\end{array}$ \\
\hline Neuroimaging & $\begin{array}{l}\text { - Collaborations to develop a standard set of imaging protocols and } \\
\text { a shared repository of neuroimaging data } \\
\text { - Prospective studies using multimodal techniques including MRI } \\
\text { and CSF proteomics to test potential pharmacological agents } \\
\text { - Prospective multicenter studies comparing the accuracy of MRI } \\
\text { techniques } \\
\text { - Formulate evidence-based guidelines for the use of quantitative } \\
\text { MRI, such as phase-contrast MRI } \\
\text { - Validation of noninvasive MRI techniques to indirectly measure } \\
\text { ICP and compliance }\end{array}$ & $\begin{array}{l}\text { - Implementation of a standard set of imaging protocols and a } \\
\text { shared repository of neuroimaging data } \\
\text { - Support methodological studies that standardize neuroimag- } \\
\text { ing devices and procedures } \\
\text { - Support multidisciplinary studies that correlate neuroimaging } \\
\text { data with both cellular and biochemical alterations, and to } \\
\text { correlate these data with clinical outcomes } \\
\text { - Support studies that validate noninvasive MRI techniques to } \\
\text { monitor critical physiological parameters }\end{array}$ \\
\hline
\end{tabular}


The Hydrocephalus Clinical Research Network (HCRN) implementation of a shunt infection protocol demonstrated that compliance with the protocol reduced shunt infection rates significantly..$^{54}$ The study and institution of quality improvement methodologies in the context of multicenter studies has provided a framework to advance care across the broader pediatric neurosurgical community.

Similarly, patient registries can provide very large numbers of patients to study relatively rare events; an example is the analysis of antibiotic-impregnated shunts. The involvement of multiple centers reduces issues related to generalizability of data or techniques. The HCRN has been an example of this vision, with 10 centers and more than 2500 patients enrolled and almost 5000 procedures tracked (http://www.hcrn.org). Networks such as the HCRN provide the infrastructure to conduct nested prospective cohort studies and RCTs.

Critical to the discussion of surgical treatment for pediatric hydrocephalus is the use of combined endoscopic third ventriculostomy (ETV) and choroid plexus cauterization (CPC). In a large cohort of Sub-Saharan patients, most of whom presented with infectious hydrocephalus, CPC significantly increased the success of ETV in infants. ${ }^{125-129}$ ETV/CPC procedures are safe with low morbidity and mortality, and long-term ETV/CPC failure and infection rates were lower than for shunts in a study in East Africa, with success rates ranging from $62 \%$ to $82 \% .{ }^{129}$ ETV success scores can be highly predictive of which patients will benefit or should have a standard shunt implanted as the principal intervention. Ongoing studies coordinated by the HCRN will help determine if these results can be translated to the broader pediatric neurosurgery population, whether the procedure has long-term durability, whether ultimate cognitive outcomes are similar to those of VP shunts, and whether removal of homeostatic and trophic factors secreted by the choroid plexus have consequences later in life. ${ }^{49,50}$

As noted, VP shunt survival has remained constant regardless of the hardware used. ${ }^{17}$ Thus, strategies to reduce proximal catheter revision rates are important. Although it may play a role in improving accuracy, the financial costs of image guidance and whether it is needed in routine cases must be evaluated. Advances in proximal catheter design have been minimal and have not been tested in RCTs. Many factors may influence proximal catheter dynamics including catheter material, number of holes, hole sizes, and other confounders such as adjuncts (flanges). Novel catheter designs are desired and should undergo RCTs to show efficacy before widespread clinical implantation.

\section{Areas of Promise and Recommendations for Treatment in Hydrocephalus in the Next 5 Years}

Bioengineering advances hold promise for the development of more physiological valve mechanisms and for reducing catheter obstruction by preventing cell and tissue adhesion (Table 3). Across both the pathophysiology section (Theme 1) and within treatment (Theme 3), a better understanding of the biological basis of catheter obstruction was needed to better guide engineering advances based on the most common causes of shunt failure. The ability to provide on-demand diagnostics in the physician's office was a voiced priority, as was the development of improved ventricular catheters and the need for improved partnership with industry.

It was a uniform recommendation that the efficacy, safety, generalizability, and longitudinal outcome of ETV/ CPC should be studied and the opportunity for a randomized trial of ETV/CPC versus VP shunting should be considered. The standardization of surgical technique and optimization of various aspects of the current practice of shunt implantation should be a priority.

\section{Theme 4: Outcome in Hydrocephalus Neuropsychological Outcomes}

Variability is a hallmark of neuropsychological outcomes in congenital and acquired hydrocephalus. 26,37,38,105 Outcome assessments should include traditional neuropsychological assessments as well as interview-based measures of adaptive behavior and rating scales. ${ }^{2}$ Adaptive behavior assessments do not simply duplicate cognitive performance assessments but can directly indicate the level of independent functioning in multiple domains.

Spina bifida with or without hydrocephalus is an important condition-related variable that influences neuropsychological outcome in children with obstructive hydrocephalus. ${ }^{38}$ It remains important to look beyond IQ to functional relevance and self-management outcomes ${ }^{16}$ and appreciate the malformations that underlie hydrocephalus in this patient population..$^{15}$ The context of the evaluation must be considered, including the emotional and family dynamics. Living with congenital brain disorders involving hydrocephalus for 30-50 years involves not only cognitive challenges originating in childhood but also new challenges emerging in adult life. Various alterations in brain morphology are implicated, including changes in frontal lobe development, thinning of white matter pathways, and issues related to memory structures within the mesial temporal lobe. While the effect is unclear in children, VP shunt revisions in adults negatively affect functional numeracy, memory function, independent living, and employment. ${ }^{105}$

Treatment of the reversible neuropsychological deficits of iNPH is a focus of study. ${ }^{9,12,21,32,35,78,119}$ Studies show an improvement in neurocognitive measures after treatment, including verbal memory, psychomotor scores, mental tracking speed, attention, independent living, and caregiver scores. ${ }^{62,77}$ Postshunting cognitive changes can precede functional recovery and may be sensitive and early markers of NPH outcome. The durability of the improvement is influenced by many factors such as shunt survival and complications, and distinguishing worsening due to progressive iNPH or other comorbidities such as vascular dementia and Alzheimer disease. ${ }^{77}$

\section{Neurological Outcomes and Quality of Life}

Focus on the quality of life in children with hydrocephalus includes the general concepts of measuring healthrelated outcomes in children and the specific challenges in improving these outcomes. ${ }^{61,63,121}$ The major self-identified issues related to quality of life in children with hydrocephalus include cognitive difficulties, behavioral difficulties, 
TABLE 3. Areas of promise and recommendations for hydrocephalus research on treatment of hydrocephalus in the next 5 years

\begin{tabular}{|c|c|c|}
\hline Theme & Areas of Promise & Recommendations \\
\hline $\begin{array}{c}\text { Bioengineering } \\
\text { Advances }\end{array}$ & $\begin{array}{l}\text { - Obstruction-resistant shunts (both proximal catheter } \\
\text { and valve) } \\
\text { - In vitro biological models for preclinical testing } \\
\text { - Implantable sensors for monitoring CSF pressure and } \\
\text { flow plus pertinent physiological data } \\
\text { - Improved understanding of desirable algorithms for CSF } \\
\text { drainage } \\
\text { - "Smart" shunts with diagnostics, advanced control, and } \\
\text { maintenance }\end{array}$ & $\begin{array}{l}\text { - Provide incentives for novel ventricular catheter design, materials } \\
\text { engineering, and antifouling technologies } \\
\text { - Support collaborative efforts between clinicians, scientists, and engi- } \\
\text { neers via program projects and/or center grants; expand NIH support } \\
\text { of STTR and SBIR grants to enhance translational research. } \\
\text { - Support advances in several engineering categories, including im- } \\
\text { plantable pressure and flow sensors } \\
\text { - Support development of realistic and reliable testing platforms (bench- } \\
\text { top and in vitro models) to advance and reduce the cost of testing } \\
\text { implantable devices. } \\
\text { - Improved animal models would be valuable for pre-IDE device devel- } \\
\text { opment and testing } \\
\text { - Refine mathematical modeling of CSF dynamics; pair with in vivo } \\
\text { knowledge of CSF dynamics } \\
\text { - Develop exquisitely controlled shunting devices }\end{array}$ \\
\hline $\begin{array}{l}\text { Surgical } \\
\quad \text { Advances }\end{array}$ & $\begin{array}{l}\text { - Refinement of surgical shunting procedures to improve } \\
\text { survival and reduce infection rates } \\
\text { - Determination of optimal ventricular catheter placement } \\
\text { - Understanding the generalizability and outcome of } \\
\text { ETV and/or CPC procedures within North American } \\
\text { populations }\end{array}$ & $\begin{array}{l}\text { - Prioritize trials to determine improved techniques for shunt survival } \\
\text { and reduced infection; great short-term potential to reduce morbidity } \\
\text { and mortality } \\
\text { - Expand enrollment in multicenter networks to increase pooled data } \\
\text { and implement RCTs } \\
\text { - Prioritize funding for longitudinal studies on outcome data in patients } \\
\text { who undergo alternative procedures such as ETV and/or CPC }\end{array}$ \\
\hline
\end{tabular}

IDE = investigational device exemption; SBIR = Small Business Innovation Research; STTR = Small Business Technology Transfer.

and headaches. Quality-of-life concerns that follow into adulthood include depression, inability to live independently, inability to drive, unemployment, substance abuse, and denial of health care. Areas in which health care providers and surgeons can influence current and future quality of life include reducing operative complications such as infections, improving access to community-based services, and improving transition into adulthood.

Intraventricular hemorrhage interrupts normal brain development, resulting in "encephalopathy of the preterm infant" and a unique neurodevelopmental phenotype of prematurity. ${ }^{42-44,47,99,109}$ The potential for additional damage to the developing brain as well as the impact of hydrocephalus on neurodevelopment of the preterm infant most certainly impact functional outcome. Outcomes are likely related to extent of initial injury, gestational age at injury, and the timing of intervention. Currently used outcome measures are linked to major outcomes that represent just a rudimentary overview so there is a need to develop more robust, granular functional outcome measures.

Changing the paradigm from "eminence-based" to "evidence-based" care requires a focus on the value of high-

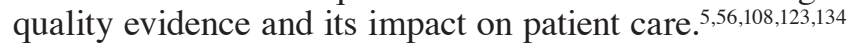
Appropriate sample size has been a major issue, with $50 \%$ of general surgical trials being underpowered. ${ }^{31,107}$ Within surgical specialties, RCTs are less common because of the surgical research culture, the difficulty of conducting surgical RCTs, limited RCT expertise among surgeons, limited infrastructure, and limited funding. In the last 20 years, the quality of surgical research is rated as very low to poor quality in more than $60 \%$ of studies. Clearly, improved surgical research calls for randomization, blinding outcomes, objective outcome measures, complete follow- up, limiting differential expertise, and enrolling sufficient patient numbers.

\section{Areas of Promise and Recommendations for Outcomes in Hydrocephalus in the Next 5 Years}

The recommendations in Table 4 apply broadly to children and adults with hydrocephalus. Specific, reliable batteries with metrics focused on the patient need to be developed and validated. Measurements of neurocognitive outcome and quality of life should be adaptable, trackable across the growth spectrum, and applicable cross-culturally. With iNPH, developing comparisons against normative age-based data and sensitive screening tools would be especially valuable in early diagnosis. ${ }^{30,82,94}$ An important issue is the need for a better understanding of the incidence and prevalence of hydrocephalus within both pediatric and adult populations and to compare aging patterns in adults with hydrocephalus against normal aging patterns.

\section{Summary}

Consensus priorities in four major areas of hydrocephalus research (causes, diagnosis, treatment, and outcomes) that have the most potential to impact patient care in the next 5 years emphasize patient-centered care and translational research. Areas of promise included evaluation of the genetics of hydrocephalus, development of models to improve our understanding of the disease, use of multidisciplinary opportunities and standardized protocols, emphasis on novel bioengineering designs, improved surgical trials, and developing validated metrics of outcome. These priorities should serve as guidelines for the hydrocephalus community at large as well as governmental and nongovernmental funding agencies in the future. 
TABLE 4. Areas of promise and recommendations for hydrocephalus research on outcome in hydrocephalus in the next 5 years

\begin{tabular}{|c|c|c|}
\hline Theme & Areas of Promise & Recommendations \\
\hline $\begin{array}{l}\text { Neuropsychological } \\
\text { Outcomes }\end{array}$ & $\begin{array}{l}\text { - Refinement of neuropsychological testing for both pediatric } \\
\text { and adult hydrocephalus patients to determine which of } \\
\text { the battery of tests are most expedient and reliable } \\
\text { - Determining which neuropsychological measures have } \\
\text { robust correlation between alterations in brain structure/ } \\
\text { morphology or functions that can be imaged with fMRI or } \\
\text { DTI } \\
\text { - Determining whether various preoperative neuropsycho- } \\
\text { logical tests can predict postoperative outcome reliably } \\
\text { - Increased efforts to record and design metrics of quality- } \\
\text { of-life measures } \\
\text { - Correlation of neurobiology with neuropsychological as- } \\
\text { sessments, i.e., to identify physiological correlates (ICP, } \\
\text { CSF genomics/proteomics, etc.) that lead to discrete } \\
\text { neuropsychological deficits }\end{array}$ & $\begin{array}{l}\text { - Undertake a concerted funding effort to support improved } \\
\text { outcomes metrics in hydrocephalus research } \\
\text { - Implement multidisciplinary efforts whereby neuropsy- } \\
\text { chologists are paired with clinicians, basic scientists, and } \\
\text { imaging researchers to more broadly correlate outcome } \\
\text { with treatment interventions and basic science findings } \\
\text { - Prioritize funding of longitudinal studies of outcomes data } \\
\text { - Provide incentives for development of hydrocephalus- } \\
\text { specific, expedient, and reliable cross-cultural neuropsy- } \\
\text { chological testing batteries }\end{array}$ \\
\hline $\begin{array}{l}\text { Neurological Outcomes } \\
\text { and Quality of Life }\end{array}$ & $\begin{array}{l}\text { - Development of appropriate outcome metrics to longitudi- } \\
\text { nally follow quality-of-life measures } \\
\text { - Implementation of more granular outcome measures in } \\
\text { patient tracking } \\
\text { - Expanded multicenter networks to provide enough power } \\
\text { within the context of outcome studies } \\
\text { - Increased efforts to bring forward appropriately powered } \\
\text { RCTs within hydrocephalus and NPH } \\
\text { - Improved tracking and potential standardization of the } \\
\text { timing of surgical treatment in premature IVH and its } \\
\text { relationship to outcome measures }\end{array}$ & $\begin{array}{l}\text { - Support funding for RCTs within hydrocephalus } \\
\text { - Support collaborations and mentorship both within and } \\
\text { outside of the hydrocephalus arena } \\
\text { - Foster multidisciplinary efforts to integrate appropriate } \\
\text { outcome metrics into all facets of hydrocephalus research } \\
\text { - Identify long-term funding opportunities to support longitu- } \\
\text { dinal studies of outcome }\end{array}$ \\
\hline
\end{tabular}

$\mathrm{fMRI}=$ functional MRI; IVH = intraventricular hemorrhage.

\section{Appendix}

\section{The Hydrocephalus Symposium Expert Panel}

Stephen A. Back, MD, PhD: Departments of Pediatrics and Neurology, Oregon Health \& Science University, Portland, Oregon Mohit Bhandari, MD: Department of Surgery and Clinical Epidemiology, McMaster University, Hamilton, Ontario, Canada

William G. Bradley, Jr, MD, PhD, FACR: Department of Radiology, University of California, San Diego, California Jerold Chun, MD, PhD: Department of Molecular Biology, The Scripps Research Institute, La Jolla, California

Paige T. Church, MD: Sunnybrook Health Sciences Centre and University of Toronto, Toronto, Ontario, Canada

Thomas J. Clement, MS: Cardiac Insight, Inc., Aqueduct Neurosciences, Inc., Seattle, Washington

Marc R. Del Bigio, MD, PhD: Department of Pathology, University of Manitoba, Winnipeg, Manitoba, Canada

Maureen Dennis, PhD: Program in Neurosciences and Mental Health and Department of Surgery, The Hospital for Sick Children and the University of Toronto, Ontario, Canada

William B. Dobyns, MD: Developmental Disorders Group, Children's Hospital Research Institute, Seattle, Washington

Richard J. Edwards, MD: Department of Neurosurgery, Frenchay Hospital, Bristol, United Kingdom

Jack M. Fletcher, PhD: Department of Psychology, University of Houston, Texas

Antonio J. Jimenez, PhD: Departamento de Biología Celular Genética y Fisiología, University of Malaga, Malaga, Spain

Abhaya V. Kulkarni, MD, PhD: Departments of Neurosurgery and Neurology, Toronto Hospital for Sick Children, Toronto, Ontario, Canada

David D. Limbrick, MD, PhD: Departments of Neurological Surgery and Pediatrics, Washington University, St. Louis, Missouri
Barry Lutz, PhD: Department of Bioengineering, University of Washington, Seattle, Washington

Jill A. Morris, PhD: Program Director, National Institute of Neurological Disease and Stroke, Bethesda, Maryland

Richard S. Morrison, PhD: Department of Neurological Surgery and the Center for Neuroproteomics, University of Washington, Seattle, Washington

Jay Riva-Cambrin, MD: Department of Neurosurgery, Division of Pediatric Neurosurgery, University of Utah, Salt Lake City, Utah

Esteban Rodriguez, MD, PhD: Instituto de Histologia y Patología, Universidad Austral de Chile Valdivia, Chile

Mark Wagshul, PhD: Department of Radiology and the Gruss MR Research Center, Albert Einstein College of Medicine, Bronx, New York

Benjamin Warf, MD: Department of Neurosurgery, Children's Hospital Boston, Massachusetts

Laurence Watkins, MD: Victor Horsley Department of Neurosurgery, National Hospital for Neurology and Neurosurgery, Queens Square, London, United Kingdom

David A. Watson: Dave Watson Engineering, San Jose, California

Andrew Zabel, PhD: Department of Neuropsychology, Kennedy Krieger Institute and Johns Hopkins School of Medicine, Baltimore, Maryland

\section{Acknowledgments}

We are grateful for financial support from the National Institutes of Health, the Hydrocephalus Association, the Hydrocephalus Clinical Research Network, Seattle Children's Hospital and Research Institute, the University of Washington, and the Seattle Children's Hydrocephalus Research Guild. We acknowledge the work of the organizing committee members: Samuel R. Browd, MD, PhD; 
Pat McAllister, PhD; Amy Anderson, BSN, RN; Dawn Mancuso, CAE, FASAE; Paul Gross; and Gavin Reed, MPH. We recognize the session directors: Esteban Rodriguez, MD, PhD; Marc R. Del Bigio, MD, PhD; David Limbrick, MD, PhD; Mark Wagshul, PhD; Barry Lutz, PhD; Jay Riva-Cambrin, MD; Jack M. Fletcher, PhD; and Abhaya V. Kulkarni, MD, PhD. The event planning committee included Sarah Fuccillo; David Su, MD; and Carroll Olson, MD. We thank Kristin Kraus, MSc, Department of Neurosurgery, University of Utah, for her excellent editorial support.

\section{References}

1. Adle-Biassette H, Saugier-Veber P, Fallet-Bianco C, Delezoide AL, Razavi F, Drouot N, et al: Neuropathological review of 138 cases genetically tested for X-linked hydrocephalus: evidence for closely related clinical entities of unknown molecular bases. Acta Neuropathol 126:427442, 2013

2. Adzick NS: Fetal surgery for spina bifida: past, present, future. Semin Pediatr Surg 22:10-17, 2013

3. Al-Dosari MS, Al-Owain M, Tulbah M, Kurdi W, Adly N, Al-Hemidan A, et al: Mutation in MPDZ causes severe congenital hydrocephalus. J Med Genet 50:54-58, 2013

4. Andresen M, Juhler M: Multiloculated hydrocephalus: a review of current problems in classification and treatment. Childs Nerv Syst 28:357-362, 2012

5. Ayeni OR, Evaniew N, Ogilvie R, Peterson DC, Denkers MR, Bhandari M: Evidence-based practice to improve outcomes of anterior cruciate ligament reconstruction. Clin Sports Med 32:71-80, 2013

6. Back SA, Riddle A, McClure MM: Maturation-dependent vulnerability of perinatal white matter in premature birth. Stroke 38 (2 Suppl):724-730, 2007

7. Balasubramaniam J, Del Bigio MR: Analysis of agedependant alteration in the brain gene expression profile following induction of hydrocephalus in rats. Exp Neurol 173:105-113, 2002

8. Balédent O, Gondry-Jouet C, Stoquart-Elsankari S, Bouzerar R, Le Gars D, Meyer ME: Value of phase contrast magnetic resonance imaging for investigation of cerebral hydrodynamics. J Neuroradiol 33:292-303, 2006

9. Bergsneider M, Black PM, Klinge P, Marmarou A, Relkin $\mathrm{N}$ : Surgical management of idiopathic normal-pressure hydrocephalus. Neurosurgery 57 (3 Suppl):S29-S39, ii-v, 2005

10. Bertolin C, Boaretto F, Barbon G, Salviati L, Lapi E, Divizia MT, et al: Novel mutations in the L1CAM gene support the complexity of L1 syndrome. J Neurol Sci 294:124-126, 2010

11. Blegvad C, Skjolding AD, Broholm H, Laursen H, Juhler M: Pathophysiology of shunt dysfunction in shunt treated hydrocephalus. Acta Neurochir (Wien) 155:1763-1772, 2013

12. Bloch O, McDermott MW: Lumboperitoneal shunts for the treatment of normal pressure hydrocephalus. J Clin Neurosci 19:1107-1111, 2012

13. Botfield H, Gonzalez AM, Abdullah O, Skjolding AD, Berry M, McAllister JP II, et al: Decorin prevents the development of juvenile communicating hydrocephalus. Brain 136:2842-2858, 2013

14. Bouzerar R, Balédent O, Bouzerar R, Meyer ME, Czosnyka M: A physical model of occlusive hydrocephalus. Clin Neurol Neurosurg 110:S4, 2008 (Abstract)

15. Brewer VR, Fletcher JM, Hiscock M, Davidson KC: Attention processes in children with shunted hydrocephalus versus attention deficit-hyperactivity disorder. Neuropsychology 15:185-198, 2001

16. Brookshire BL, Fletcher JM, Bohan TP, Landry SH, Davidson KC, Francis DJ: Verbal and nonverbal skill dis- crepancies in children with hydrocephalus: a five-year longitudinal follow-up. J Pediatr Psychol 20:785-800, 1995

17. Browd SR, Gottfried ON, Ragel BT, Kestle JR: Failure of cerebrospinal fluid shunts: part II: overdrainage, loculation, and abdominal complications. Pediatr Neurol 34:171-176, 2006

18. Browd SR, Ragel BT, Gottfried ON, Kestle JR: Failure of cerebrospinal fluid shunts: part I: Obstruction and mechanical failure. Pediatr Neurol 34:83-92, 2006

19. Calcagni ML, Taralli S, Mangiola A, Indovina L, Lavalle M, De Bonis P, et al: Regional cerebral metabolic rate of glucose evaluation and clinical assessment in patients with idiopathic normal-pressure hydrocephalus before and after ventricular shunt placement: a prospective analysis. Clin Nucl Med 38:426-431, 2013

20. Carter CS, Vogel TW, Zhang Q, Seo S, Swiderski RE, Moninger TO, et al: Abnormal development of NG2+PDGFR- $\alpha+$ neural progenitor cells leads to neonatal hydrocephalus in a ciliopathy mouse model. Nat Med 18:1797-1804, 2012

21. Chaudhry P, Kharkar S, Heidler-Gary J, Hillis AE, Newhart M, Kleinman JT, et al: Characteristics and reversibility of dementia in normal pressure hydrocephalus. Behav Neurol 18:149-158, 2007

22. Del Bigio MR: Cellular damage and prevention in childhood hydrocephalus. Brain Pathol 14:317-324, 2004

23. Del Bigio MR: Neuropathology and structural changes in hydrocephalus. Dev Disabil Res Rev 16:16-22, 2010

24. Del Bigio MR, Khan OH, da Silva Lopes L, Juliet PA: Cerebral white matter oxidation and nitrosylation in young rodents with kaolin-induced hydrocephalus. J Neuropathol Exp Neurol 71:274-288, 2012

25. Del Bigio MR, Wilson MJ, Enno T: Chronic hydrocephalus in rats and humans: white matter loss and behavior changes. Ann Neurol 53:337-346, 2003

26. Dennis M, Nelson R, Jewell D, Fletcher JM: Prospective memory in adults with spina bifida. Childs Nerv Syst 26:1749-1755, 2010

27. Di Curzio DL, Buist RJ, Del Bigio MR: Reduced subventricular zone proliferation and white matter damage in juvenile ferrets with kaolin-induced hydrocephalus. Exp Neurol 248: $112-128,2013$

28. Di Curzio DL, Turner-Brannen E, Del Bigio MR: Oral antioxidant therapy for juvenile rats with kaolin-induced hydrocephalus. Fluids Barriers CNS 11:23, 2014

29. Drielsma A, Jalas C, Simonis N, Désir J, Simanovsky N, Pirson I, et al: Two novel CCDC88C mutations confirm the role of DAPLE in autosomal recessive congenital hydrocephalus. J Med Genet 49:708-712, 2012

30. Duinkerke A, Williams MA, Rigamonti D, Hillis AE: Cognitive recovery in idiopathic normal pressure hydrocephalus after shunt. Cogn Behav Neurol 17:179-184, 2004

31. Farrokhyar F, Reddy D, Poolman RW, Bhandari M: Why perform a priori sample size calculation? Can J Surg 56:207-213, 2013

32. Feick D, Sickmond J, Liu L, Metellus P, Williams M, Rigamonti D, et al: Sensitivity and predictive value of occupational and physical therapy assessments in the functional evaluation of patients with suspected normal pressure hydrocephalus. J Rehabil Med 40:715-720, 2008

33. Frim DM, Lathrop D: Telemetric assessment of intracranial pressure changes consequent to manipulations of the Codman-Medos programmable shunt valve. Pediatr Neurosurg 33:237-242, 2000

34. Frischholz M, Sarmento L, Wenzel M, Aquilina K, Edwards R, Coakham HB: Telemetric implantable pressure sensor for short- and long-term monitoring of intracranial pressure. Conf Proc IEEE Eng Med Biol Soc 2007:514, 2007 
35. Gallia GL, Rigamonti D, Williams MA: The diagnosis and treatment of idiopathic normal pressure hydrocephalus. Nat Clin Pract Neurol 2:375-381, 2006

36. Guerra M: Neural stem cells: are they the hope of a better life for patients with fetal-onset hydrocephalus? Fluids Barriers CNS 11:7, 2014

37. Hampton LE, Fletcher JM, Cirino P, Blaser S, Kramer LA, Dennis M: Neuropsychological profiles of children with aqueductal stenosis and spina bifida myelomeningocele. J Int Neuropsychol Soc 19:127-136, 2013

38. Hampton LE, Fletcher JM, Cirino PT, Blaser S, Kramer LA, Drake J, et al: Hydrocephalus status in spina bifida: an evaluation of variations in neuropsychological outcomes. J Neurosurg Pediatr 8:289-298, 2011

39. Harris CA, McAllister JP II: What we should know about the cellular and tissue response causing catheter obstruction in the treatment of hydrocephalus. Neurosurgery 70:15891602,2012

40. Hashimoto M, Ishikawa M, Mori E, Kuwana N: Diagnosis of idiopathic normal pressure hydrocephalus is supported by MRI-based scheme: a prospective cohort study. Cerebrospinal Fluid Res 7:18, 2010

41. Heussinger N, Eyüpoglu IY, Ganslandt O, Finzel S, Trollmann R, Jüngert J: Ultrasound-guided neuronavigation improves safety of ventricular catheter insertion in preterm infants. Brain Dev 35:905-911, 2013

42. Hudgins RJ: Posthemorrhagic hydrocephalus of infancy. Neurosurg Clin N Am 12:743-751, ix, 2001

43. Hunt RW, Warfield SK, Wang H, Kean M, Volpe JJ, Inder TE: Assessment of the impact of the removal of cerebrospinal fluid on cerebral tissue volumes by advanced volumetric 3D-MRI in posthaemorrhagic hydrocephalus in a premature infant. J Neurol Neurosurg Psychiatry 74:658-660, 2003

44. Inagaki T, Kawaguchi T, Yamahara T, Kitamura N, Ryu T, Kinoshita Y, et al: Management of intraventricular hemorrhage in preterm infants with low birth weight. Acta Neurochir Suppl 113:173-175, 2012

45. Ivkovic M, Liu B, Ahmed F, Moore D, Huang C, Raj A, et al: Differential diagnosis of normal pressure hydrocephalus by MRI mean diffusivity histogram analysis. AJNR Am J Neuroradiol 34:1168-1174, 2013

46. Jang SH, Choi BY, Chang CH, Jung YJ, Byun WM, Kim $\mathrm{SH}$, et al: The effects of hydrocephalus on the periventricular white matter in intracerebral hemorrhage: a diffuser tensor imaging study. Int J Neurosci 123:420-424, 2013

47. Jary S, De Carli A, Ramenghi LA, Whitelaw A: Impaired brain growth and neurodevelopment in preterm infants with posthaemorrhagic ventricular dilatation. Acta Paediatr 101:743-748, 2012

48. Jeppsson A, Zetterberg H, Blennow K, Wikkels $\varnothing$ C: Idiopathic normal-pressure hydrocephalus: pathophysiology and diagnosis by CSF biomarkers. Neurology 80:13851392,2013

49. Johanson C, McMillan P, Tavares R, Spangenberger A, Duncan J, Silverberg G, et al: Homeostatic capabilities of the choroid plexus epithelium in Alzheimer's disease. Cerebrospinal Fluid Res 1:3, 2004

50. Johanson CE: The choroid plexus-CSF nexus gateway to the brain, in Conn PM (ed): Neuroscience in Medicine, ed 2. Totowa, NJ: Humana Press, 2006, pp 165-195

51. Kaestner S, Dimitriou I: TGF beta1 and TGF beta2 and their role in posthemorrhagic hydrocephalus following SAH and IVH. J Neurol Surg A Cent Eur Neurosurg 74:279284,2013

52. Kanemura Y, Okamoto N, Sakamoto H, Shofuda T, Kamiguchi H, Yamasaki M: Molecular mechanisms and neuroimaging criteria for severe L1 syndrome with X-linked hydrocephalus. J Neurosurg 105 (5 Suppl):403-412, 2006

53. Kenwrick S, Doherty P: Neural cell adhesion molecule L1: relating disease to function. BioEssays 20:668-675, 1998
54. Kestle JRW, Riva-Cambrin J, Wellons JC III, Kulkarni AV, Whitehead WE, Walker ML, et al: A standardized protocol to reduce cerebrospinal fluid shunt infection: the Hydrocephalus Clinical Research Network Quality Improvement Initiative. J Neurosurg Pediatr 8:22-29, 2011

55. Khan F, Shamim MS, Rehman A, Bari ME: Analysis of factors affecting ventriculoperitoneal shunt survival in pediatric patients. Childs Nerv Syst 29:791-802, 2013

56. Khan $\mathrm{H}$, Hussain $\mathrm{N}$, Bhandari $\mathrm{M}$ : The influence of large clinical trials in orthopaedic trauma: Do they change practice? J Orthop Trauma 27:e268-e274, 2013

57. Khan OH, Enno TL, Del Bigio MR: Brain damage in neonatal rats following kaolin induction of hydrocephalus. Exp Neurol 200:311-320, 2006

58. Khan OH, McPhee LC, Moddemann LN, Del Bigio MR: Calcium antagonism in neonatal rats with kaolin-induced hydrocephalus. J Child Neurol 22:1161-1166, 2007

59. Kharkar S, Shuck J, Kapoor S, Batra S, Williams MA, Rigamonti D: Radionuclide shunt patency study for evaluation of suspected ventriculoperitoneal shunt malfunction in adults with normal pressure hydrocephalus. Neurosurgery 64:909-918, 2009

60. Kim H, Moore SA, Johnston MG: Potential for intranasal drug delivery to alter CSF outflow via the nasal turbinate lymphatics. Fluids Barriers CNS 11:4, 2014

61. Klinge P, Hellström P, Tans J, Wikkels $\varnothing$ C: One-year outcome in the European multicentre study on iNPH. Acta Neurol Scand 126:145-153, 2012

62. Koivisto AM, Alafuzoff I, Savolainen S, Sutela A, Rummukainen J, Kurki M, et al: Poor cognitive outcome in shunt-responsive idiopathic normal pressure hydrocephalus. Neurosurgery 72:1-8, 2013

63. Kulkarni AV, Donnelly R, Shams I: Comparison of Hydrocephalus Outcome Questionnaire scores to neuropsychological test performance in school-aged children. J Neurosurg Pediatr 8:396-401, 2011

64. Lahiri DK, Ray B: Abnormal cerebrospinal fluid (CSF) dynamics in Alzheimer's disease and normal pressure hydrocephalus: CSF-amyloid $\beta$ precursor protein metabolites as possible biomarkers. Eur J Neurol 20:211-213, 2013

65. Lee JH, Park DH, Back DB, Lee JY, Lee CI, Park KJ, et al: Comparison of cerebrospinal fluid biomarkers between idiopathic normal pressure hydrocephalus and subarachnoid hemorrhage-induced chronic hydrocephalus: a pilot study. Med Sci Monit 18:PR19-PR25, 2012

66. Lee SA, Pinney JR, Khialeeva E, Bergsneider M, Judy JW: Functional evaluation of magnetic microactuators for removing biological accumulation: an in vitro study. Conf Proc IEEE Eng Med Biol Soc 2008:947-950, 2008

67. Leinonen V, Menon LG, Carroll RS, Dello Iacono D, Grevet J, Jääskeläinen JE, et al: Cerebrospinal fluid biomarkers in idiopathic normal pressure hydrocephalus. Int J Alzheimers Dis 2011:312526, 2011

68. Levitt MR, O’Neill BR, Ishak GE, Khanna PC, Temkin NR, Ellenbogen RG, et al: Image-guided cerebrospinal fluid shunting in children: catheter accuracy and shunt survival. J Neurosurg Pediatr 10:112-117, 2012

69. Li X, Miyajima M, Mineki R, Taka H, Murayama K, Arai $\mathrm{H}$ : Analysis of cerebellum proteomics in the hydrocephalic H-Tx rat. Neuroreport 16:571-574, 2005

70. Li X, Miyajima M, Mineki R, Taka H, Murayama K, Arai $\mathrm{H}$ : Analysis of potential diagnostic biomarkers in cerebrospinal fluid of idiopathic normal pressure hydrocephalus by proteomics. Acta Neurochir (Wien) 148:859-864, 2006

71. Limbrick DD Jr, Lake S, Talcott M, Alexander B, Wight S, Willie JT, et al: The baric probe: a novel long-term implantable intracranial pressure monitor with ultrasound-based interrogation. J Neurosurg Pediatr 10:518-524, 2012 
72. Lin X, Liu B, Yang X, Yue X, Diao L, Wang J, et al: Genetic deletion of Rnd3 results in aqueductal stenosis leading to hydrocephalus through up-regulation of Notch signaling. Proc Natl Acad Sci U S A 110:8236-8241, 2013

73. Lipina R, Reguli S, Novácková L, Podesvová H, Brichtová E: Relation between TGF-beta 1 levels in cerebrospinal fluid and ETV outcome in premature newborns with posthemorrhagic hydrocephalus. Childs Nerv Syst 26:333-341, 2010

74. Lundin F, Tisell A, Leijon G, Leinhard OD, Davidsson L, Grönqvist A, et al: Preoperative and postoperative 1H-MR spectroscopy changes in frontal deep white matter and the thalamus in idiopathic normal pressure hydrocephalus. J Neurol Neurosurg Psychiatry 84:188-193, 2013

75. Lutz BR, Venkataraman P, Browd SR: New and improved ways to treat hydrocephalus: pursuit of a smart shunt. Surg Neurol Int 4 (Suppl 1):S38-S50, 2013

76. Madsen JR, Abazi GS, Fleming L, Proctor M, Grondin R, Magge S, et al: Evaluation of the ShuntCheck noninvasive thermal technique for shunt flow detection in hydrocephalic patients. Neurosurgery 68:198-205, discussion 205, 2011

77. Malm J, Graff-Radford NR, Ishikawa M, Kristensen B, Leinonen V, Mori E, et al: Influence of comorbidities in idiopathic normal pressure hydrocephalus - research and clinical care. A report of the ISHCSF task force on comorbidities in INPH. Fluids Barriers CNS 10:22, 2013

78. Mandir AS, Hilfiker J, Thomas G, Minahan RE, Crawford TO, Williams MA, et al: Extrapyramidal signs in normal pressure hydrocephalus: an objective assessment. Cerebrospinal Fluid Res 4:7, 2007

79. McAllister JP II: Pathophysiology of congenital and neonatal hydrocephalus. Semin Fetal Neonatal Med 17:285-294, 2012

80. McAllister JP II, Chovan P: Neonatal hydrocephalus. Mechanisms and consequences. Neurosurg Clin N Am 9:73-93, 1998

81. McAllister JP II, Miller JM: Minocycline inhibits glial proliferation in the H-Tx rat model of congenital hydrocephalus. Cerebrospinal Fluid Res 7:7, 2010

82. McGirt MJ, Woodworth G, Coon AL, Thomas G, Williams MA, Rigamonti D: Diagnosis, treatment, and analysis of long-term outcomes in idiopathic normal-pressure hydrocephalus. Neurosurgery 57:699-705, 2005

83. Merhar S: Biomarkers in neonatal posthemorrhagic hydrocephalus. Neonatology 101:1-7, 2012

84. Miller JM, Kumar R, McAllister JP II, Krause GS: Gene expression analysis of the development of congenital hydrocephalus in the H-Tx rat. Brain Res 1075:36-47, 2006

85. Mirzaa GM, Rivière JB, Dobyns WB: Megalencephaly syndromes and activating mutations in the PI3K-AKT pathway: MPPH and MCAP. Am J Med Genet C Semin Med Genet 163C: $122-130,2013$

86. Miyajima M, Nakajima M, Ogino I, Miyata H, Motoi Y, Arai $\mathrm{H}$ : Soluble amyloid precursor protein $\alpha$ in the cerebrospinal fluid as a diagnostic and prognostic biomarker for idiopathic normal pressure hydrocephalus. Eur J Neurol 20:236-242, 2013

87. Moghekar A, Rigamonti D: Neuroradiological diagnosis of idiopathic normal-pressure hydrocephalus: the search for the Holy Grail. Ann Neurol 66:436-437, 2009

88. Momani L, Alkharabsheh AR, Al-Nuaimy W: Design of an intelligent and personalised shunting system for hydrocephalus. Conf Proc IEEE Eng Med Biol Soc 2008:779-782, 2008

89. Morales DM, Townsend RR, Malone JP, Ewersmann CA, Macy EM, Inder TE, et al: Alterations in protein regulators of neurodevelopment in the cerebrospinal fluid of infants with posthemorrhagic hydrocephalus of prematurity. Mol Cell Proteomics 11:M111 011973, 2012

90. Naftel RP, Safiano NA, Falola MI, Shannon CN, Wellons
JC III, Johnston JM Jr: Technology preferences among caregivers of children with hydrocephalus. J Neurosurg Pediatr 11:26-36, 2013

91. Oliver C, González CA, Alvial G, Flores CA, Rodríguez EM, Bátiz LF: Disruption of CDH2/N-cadherin-based adherens junctions leads to apoptosis of ependymal cells and denudation of brain ventricular walls. J Neuropathol Exp Neurol 72:846-860, 2013

92. Orakcioglu B, Beynon C, Kentar MM, Eymann R, Kiefer M, Sakowitz OW: Intracranial pressure telemetry: first experience of an experimental in vivo study using a new device. Acta Neurochir Suppl 114:105-110, 2012

93. Patel S, Lee EB, Xie SX, Law A, Jackson EM, Arnold SE, et al: Phosphorylated tau/amyloid beta 1-42 ratio in ventricular cerebrospinal fluid reflects outcome in idiopathic normal pressure hydrocephalus. Fluids Barriers CNS 9:7, 2012

94. Pujari S, Kharkar S, Metellus P, Shuck J, Williams MA, Rigamonti D: Normal pressure hydrocephalus: longterm outcome after shunt surgery. J Neurol Neurosurg Psychiatry 79:1282-1286, 2008

95. Qureshi AI, Williams MA, Razumovsky AY, Hanley DF: Magnetic resonance imaging, unstable intracranial pressure and clinical outcome in patients with normal pressure hydrocephalus. Acta Neurochir Suppl 71:354-356, 1998

96. Reddy GK, Bollam P, Caldito G: Long-term outcomes of ventriculoperitoneal shunt surgery in patients with hydrocephalus. World Neurosurg 81:404-410, 2014

97. Reddy GK, Bollam P, Caldito G, Guthikonda B, Nanda A: Ventriculoperitoneal shunt surgery outcome in adult transition patients with pediatric-onset hydrocephalus. Neurosurgery 70:380-389, 2012

98. Rinne JO, Frantzen J, Leinonen V, Lonnrot K, Laakso A, Virtanen KA, et al: Prospective flutemetamol positron emission tomography and histopathology in normal pressure hydrocephalus. Neurodegener Dis 13:237-245, 2014

99. Riva-Cambrin J, Shannon CN, Holubkov R, Whitehead WE, Kulkarni AV, Drake J, et al: Center effect and other factors influencing temporization and shunting of cerebrospinal fluid in preterm infants with intraventricular hemorrhage. J Neurosurg Pediatr 9:473-481, 2012

100. Roales-Buján R, Páez P, Guerra M, Rodríguez S, Vío K, Ho-Plagaro A, et al: Astrocytes acquire morphological and functional characteristics of ependymal cells following disruption of ependyma in hydrocephalus. Acta Neuropathol 124:531-546, 2012

101. Robinson S: Neonatal posthemorrhagic hydrocephalus from prematurity: pathophysiology and current treatment concepts. J Neurosurg Pediatr 9:242-258, 2012

102. Rodríguez EM, Guerra MM, Vío K, González C, Ortloff A, Bátiz LF, et al: A cell junction pathology of neural stem cells leads to abnormal neurogenesis and hydrocephalus. Biol Res 45:231-242, 2012

103. Schrander-Stumpel C, Höweler C, Jones M, Sommer A, Stevens C, Tinschert S, et al: Spectrum of X-linked hydrocephalus (HSAS), MASA syndrome, and complicated spastic paraplegia (SPG1): Clinical review with six additional families. Am J Med Genet 57:107-116, 1995

104. Scollato A, Terreni A, Caldini A, Salvadori B, Gallina P, Francese $\mathrm{S}$, et al: CSF proteomic analysis in patients with normal pressure hydrocephalus selected for the shunt: CSF biomarkers of response to surgical treatment. Neurol Sci 31:283-291, 2010

105. Scott MA, Fletcher JM, Brookshire BL, Davidson KC, Landry SH, Bohan TC, et al: Memory functions in children with early hydrocephalus. Neuropsychology 12:578-589, 1998

106. Segovia KN, McClure M, Moravec M, Luo NL, Wan Y, Gong X, et al: Arrested oligodendrocyte lineage matura- 
tion in chronic perinatal white matter injury. Ann Neurol 63:520-530, 2008

107. Singh JA, Murphy S, Bhandari M: Trial sample size, but not trial quality, is associated with positive study outcome. $\mathbf{J}$ Clin Epidemiol 63:154-162, 2010

108. Slobogean GP, Sprague S, Bhandari M: The tactics of large randomized trials. J Bone Joint Surg Am 94 (Suppl 1): 1923,2012

109. Srinivasakumar P, Limbrick D, Munro R, Mercer D, Rao R, Inder T, et al: Posthemorrhagic ventricular dilatation-impact on early neurodevelopmental outcome. Am J Perinatol 30:207-214, 2013

110. Stagno V, Navarrete EA, Mirone G, Esposito F: Management of hydrocephalus around the world. World Neurosurg 79:S23.e17-S23.e20, 2013

111. Stehlin E, Malpas S, Heppner P, Hu P, Lim M, Budgett D: Implantable ICP monitor for improved hydrocephalus management. Acta Neurochir Suppl 114:101-104, 2012

112. Talab R, Valis M, Rehak S, Krejsek J: Abnormalities of tauprotein and beta-amyloid in brain ventricle cerebrospinal fluid. Neuroendocrinol Lett 30:647-651, 2009

113. Tarkowski E, Liljeroth AM, Minthon L, Tarkowski A, Wallin A, Blennow K: Cerebral pattern of pro- and antiinflammatory cytokines in dementias. Brain Res Bull 61:255-260, 2003

114. Tarkowski E, Tullberg M, Fredman P, Wikkelsö C: Normal pressure hydrocephalus triggers intrathecal production of TNF-alpha. Neurobiol Aging 24:707-714, 2003

115. Tarnaris A, Toma AK, Chapman MD, Keir G, Kitchen ND, Watkins LD: Use of cerebrospinal fluid amyloid- $\beta$ and total tau protein to predict favorable surgical outcomes in patients with idiopathic normal pressure hydrocephalus. J Neurosurg 115:145-150, 2011

116. Tarnaris A, Toma AK, Kitchen ND, Watkins LD: Ongoing search for diagnostic biomarkers in idiopathic normal pressure hydrocephalus. Biomarkers Med 3:787-805, 2009

117. Teipel SJ, Grothe M, Lista S, Toschi N, Garaci FG, Hampel $\mathrm{H}$ : Relevance of magnetic resonance imaging for early detection and diagnosis of Alzheimer disease. Med Clin North Am 97:399-424, 2013

118. Thomale UW, Knitter T, Schaumann A, Ahmadi SA, Ziegler P, Schulz M, et al: Smartphone-assisted guide for the placement of ventricular catheters. Childs Nerv Syst 29:131-139, 2013

119. Thomas G, McGirt MJ, Woodworth G, Heidler J, Rigamonti D, Hillis AE, et al: Baseline neuropsychological profile and cognitive response to cerebrospinal fluid shunting for idiopathic normal pressure hydrocephalus. Dement Geriatr Cogn Disord 20: 163-168, 2005

120. Toma AK, Tarnaris A, Kitchen ND, Watkins LD: Working towards patient oriented outcome assessment in normal pressure hydrocephalus, what is the most important? Acta Neurochir (Wien) 153:177-180, 2011

121. Vinchon M, Rekate H, Kulkarni AV: Pediatric hydrocephalus outcomes: a review. Fluids Barriers CNS 9:18, 2012

122. Vogel P, Read RW, Hansen GM, Payne BJ, Small D, Sands AT, et al: Congenital hydrocephalus in genetically engineered mice. Vet Pathol 49:166-181, 2012

123. Wagshul ME, Eide PK, Madsen JR: The pulsating brain: A review of experimental and clinical studies of intracranial pulsatility. Fluids Barriers CNS 8:5, 2011

124. Walter SD, Ismaila AS, Cook DJ, Bhandari M, Tikkinen KA, Guyatt GH: Clinical experience may affect clinician compliance with assigned treatment in randomized trials. J Clin Epidemiol 66:768-774, 2013

125. Warf BC: Congenital idiopathic hydrocephalus of infancy: the results of treatment by endoscopic third ventriculostomy with or without choroid plexus cauterization and suggestions for how it works. Childs Nerv Syst 29:935-940, 2013
126. Warf BC: The impact of combined endoscopic third ventriculostomy and choroid plexus cauterization on the management of pediatric hydrocephalus in developing countries. World Neurosurg 79 (2 Suppl):S23.e13-e.15, 2013

127. Warf BC, Bhai S, Kulkarni AV, Mugamba J: Shunt survival after failed endoscopic treatment of hydrocephalus. J Neurosurg Pediatr 10:463-470, 2012

128. Warf BC, Campbell JW, Riddle E: Initial experience with combined endoscopic third ventriculostomy and choroid plexus cauterization for post-hemorrhagic hydrocephalus of prematurity: the importance of prepontine cistern status and the predictive value of FIESTA MRI imaging. Childs Nerv Syst 27:1063-1071, 2011

129. Warf BC, Tracy S, Mugamba J: Long-term outcome for endoscopic third ventriculostomy alone or in combination with choroid plexus cauterization for congenital aqueductal stenosis in African infants. J Neurosurg Pediatr 10:108111,2012

130. Waybright T, Avellino AM, Ellenbogen RG, Hollinger BJ, Veenstra TD, Morrison RS: Characterization of the human ventricular cerebrospinal fluid proteome obtained from hydrocephalic patients. J Proteomics 73:1156-1162, 2010

131. Welschehold S, Schmalhausen E, Dodier P, Vulcu S, Oertel $J$, Wagner W, et al: First clinical results with a new telemetric intracranial pressure-monitoring system. Neurosurgery 70 (1 Suppl Operative):44-49, 2012

132. Whitehead WE, Riva-Cambrin J, Wellons JC III, Kulkarni AV, Browd S, Limbrick D, et al: Factors associated with ventricular catheter movement and inaccurate catheter location: post hoc analysis of the hydrocephalus clinical research network ultrasound-guided shunt placement study. J Neurosurg Pediatr 14:173-178, 2014

133. Williams MA, McAllister JP, Walker ML, Kranz DA, Bergsneider M, Del Bigio MR, et al: Priorities for hydrocephalus research: report from a National Institutes of Health-sponsored workshop. J Neurosurg 107 (5 Suppl):345-357, 2007

134. Yamada S, Tsuchiya K, Bradley WG: Current and emerging MR imaging techniques for the diagnosis and management of CSF flow disorders: a review of phase-contrast and time-spatial labeling inversion pulse. Am J Neuroradiol 36:623-630, 2015

135. Yarascavitch BA, Chuback JE, Almenawer SA, Reddy K, Bhandari M: Levels of evidence in the neurosurgical literature: more tribulations than trials. Neurosurgery 71:11311138,2012

136. Yuan W, McKinstry RC, Shimony JS, Altaye M, Powell SK, Phillips JM, et al: Diffusion tensor imaging properties and neurobehavioral outcomes in children with hydrocephalus. AJNR Am J Neuroradiol 34:439-445, 2013

137. Zhang S, Chen D, Huang C, Bao J, Wang Z: Expression of HGF, MMP-9 and TGF- $\beta 1$ in the CSF and cerebral tissue of adult rats with hydrocephalus. Int J Neurosci 123:392-399, 2013

\section{Author Contributions}

Conception and design: Browd, McAllister. Acquisition of data: Browd, McAllister. Drafting the article: Browd, McAllister. Critically revising the article: all authors. Reviewed submitted version of manuscript: all authors. Approved the final version of the manuscript on behalf of all authors: Browd. Administrative/technical/ material support: Gross.

\section{Correspondence}

Samuel R. Browd, Department of Neurosurgery, Seattle Children's Hospital, 4800 Sand Point Way NE, Seattle, WA 98105. email: samuel.browd@seattlechildrens.org. 